\title{
CrystEngComm
}

\section{Enhanced phosphorescence in dibenzophosphole chalcogenide mixed crystal $\uparrow$}

\author{
Ryota Kabe, ${ }^{a}$ Vincent M. Lynch ${ }^{b}$ and Pavel Anzenbacher, Jr. ${ }^{* a}$ \\ Received 31st March 2011, Accepted 2nd June 2011 \\ DOI: 10.1039/c1ce05388d
}

The single crystals of 9-phenyl-9-dibenzophosphole chalcogenides \{oxide (1), sulfide (2) and selenide (3) $\}$ and a mixed crystal of $\mathbf{2}$ and $\mathbf{3}$ have been prepared and characterized by X-ray diffraction analysis. Several intermolecular interactions such as $\pi-\pi$ and Se-H were observed in the mixed crystal of $\mathbf{2}$ and 3. The mixed crystal of $\mathbf{2}$ and $\mathbf{3}$ exhibited enhanced phosphorescence compared to the pure constituent crystal (2 or $\mathbf{3})$ at low temperature.

\section{Introduction}

Organic electronic devices such as organic light-emitting diodes (OLEDs), ${ }^{1}$ photovoltaic devices (OPVs) ${ }^{2}$ and field-effect transistors (OFETs), ${ }^{3}$ receive a great deal of attention as low-cost and light-weight alternatives to silicon semiconductors. ${ }^{4}$ The solidstate morphology of organic materials plays an important role in the performance characteristics of organic electronic devices. Since the grain boundaries are eliminated and concentration of traps is minimized in single crystals, they are investigated to understand the solid-state electrical and photonic characteristics of organic semiconductors. ${ }^{5}$ For example, single crystal OFETs (SC-OFETs) show excellent carrier mobility compared to the vapour deposited films. ${ }^{6}$ Moreover, light emitting SC-OFETs were reported from some organic single crystals. ${ }^{7}$ However, the solid-state optical properties of organic materials are less well understood because the emission spectra are strongly influenced by their morphology. ${ }^{8}$ In particular, the intermolecular interactions in solid state and single crystals often induce self-quenching or concentration quenching. ${ }^{9}$ To reduce the concentration quenching in organic electronics, a doping technique has been widely applied. ${ }^{10}$ However, the number of reports on crystal doping is limited because of the difficulty of preparing doped crystals. ${ }^{11,12}$ Thus, in organic optoelectronics it is important to satisfy both high mobility and desired optical property requirements.

From the standpoint of materials chemistry, $\pi$-conjugated phosphorus compounds are very interesting materials as they exhibit peculiar electronic structure due to intramolecular interactions between the endocyclic $\pi$-system and $\sigma$-orbital of the exocyclic $\mathrm{P}-\mathrm{C}$ bond. ${ }^{13}$ There are several reports on

\footnotetext{
${ }^{a}$ Department of Chemistry and Center for Photochemical Sciences, Bowling Green State University, Bowling Green, Ohio, 43403, USA. E-mail: pavel@ bgsu.edu; Fax: +1 419-372-9809; Tel: +1 419-372-2080

${ }^{b}$ Department of Chemistry and Biochemistry, University of Texas at Austin, Austin, TX, 78712-0165, USA

$\dagger$ Electronic supplementary information (ESI) available: ${ }^{31} \mathrm{P}$ NMR spectra and CIF data for mixed crsytal of 2 and 3. CCDC reference numbers 819622 and 819623 . For ESI and crystallographic data in CIF or other electronic format see DOI: $10.1039 / \mathrm{clce} 05388 \mathrm{~d}$
}

application of $\pi$-conjugated phosphorus compounds as OLED emitter $^{13}$ and electron transporting materials. ${ }^{14}$ Recently, we have investigated the photophysical properties of 9-phenyl-9dibenzophosphole chalcogenides (oxide, sulfide, and selenide) (Fig. 1). ${ }^{15}$ We investigated solid-state interactions of dibenzophosphole chalcogenides and their potential application as electron transporting materials. Herein, we report on the crystallographic properties of 9-phenyl-9-dibenzophosphole chalcogenides and compare these with the mixed crystal structure and optical properties of 9-phenyl-9-dibenzophosphole sulphideselenide. The mixed crystal is expected to reduce the concentration quenching in the crystalline state. We discuss the structural changes and enhanced phosphorescence in the mixed crystal.

\section{Experimental}

9-Phenyl-9-dibenzophosphole chalcogenides were prepared according to the literature. ${ }^{16}{ }^{31} \mathrm{P}$ NMR spectra were recorded using a Varian Unity Plus spectrometer (400 MHz). The chemical shifts were referenced to triphenylphosphine oxide (27 ppm). Photoluminescence spectra were recorded on a single-photoncounting spectrofluorimeter (Edinburgh Analytical Instruments FLSP 920) equipped with a pulsed Xe flash-lamp ( $\mu$ F920H, 200 $900 \mathrm{~nm}, 10-100 \mathrm{~Hz}$ ) for time-gated experiments. Phosphorescence spectra were recorded at $77 \mathrm{~K}$ using liquid nitrogen. Single crystal luminescence spectra were measured in sealed quartz tubes filled with Ar.

\section{X-Ray experimental}

The single crystals of $\mathbf{1 - 3}$ were prepared by sublimation. The mixed crystal of $\mathbf{2}$ and $\mathbf{3}$ was prepared by slow evaporation from

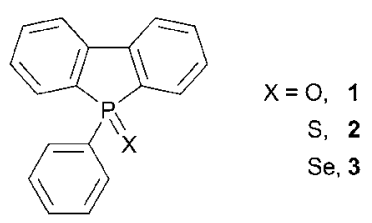

Fig. 1 Chemical structures of dibenzophosphole chalcogenides. 


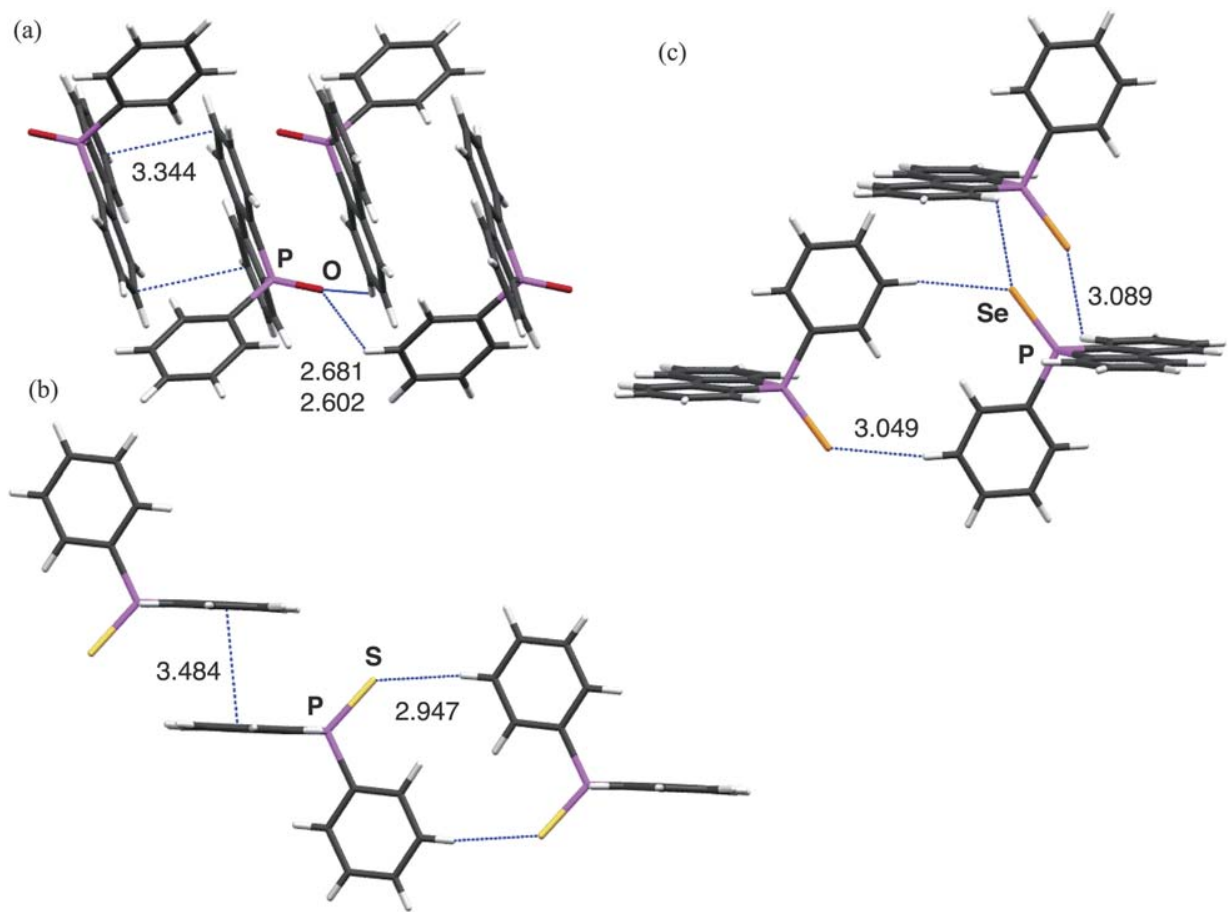

Fig. 2 Intermolecular interactions in single crystals of $\mathbf{1}$ (a), 2 (b) and 3 (c).

a $\mathrm{CH}_{2} \mathrm{Cl}_{2} /$ hexane solution of a $1: 1$ mixture of $\mathbf{2}$ and $\mathbf{3}$. The data for samples $\mathbf{1}$ and $\mathbf{2}$ were collected at $153 \mathrm{~K}$ on a Nonius Kappa $\mathrm{CCD}$ and using an Oxford Cryostream low temperature device. Data for 3 were collected at $223 \mathrm{~K}$ on a Rigaku SCX-Mini diffractometer with a Mercury CCD using a Rigaku Tec 50 lowtemperature device. Data for mixed crystal of $\mathbf{2}$ and $\mathbf{3}$ were collected at $100 \mathrm{~K}$ on a Rigaku AFC-12 with a Saturn $724+$ CCD using a Rigaku XStream low-temperature device.

All data were collected using a graphite monochromator with Mo-K $\alpha$ radiation $(\lambda=0.71075 \AA)$. Data reduction for $\mathbf{1}$ and $\mathbf{2}$ were performed using DENZO-SMN. ${ }^{17}$ Data reduction for $\mathbf{3}$ and mixed crystal were performed using the Rigaku Americas Corporation's Crystal Clear version $1.40 .{ }^{18}$ The structure was solved

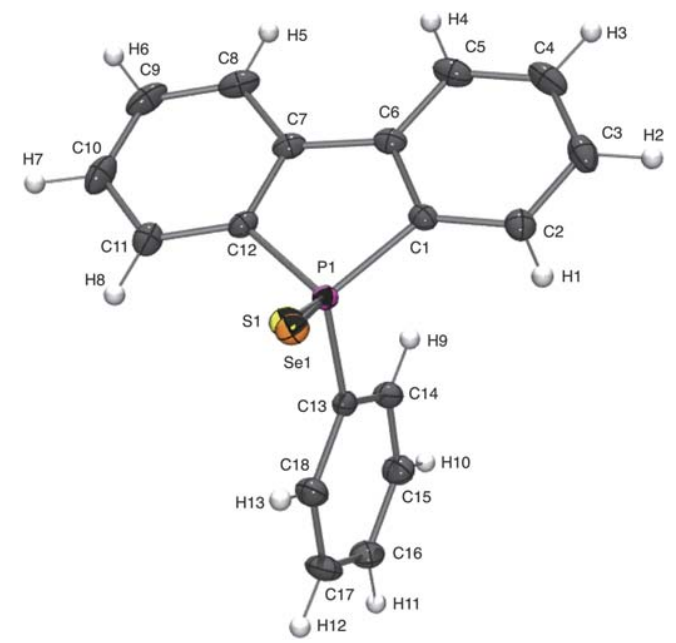

Fig. 3 ORTEP structure of a mixed crystal of 2 and 3. Thermal ellipsoids are scaled to the $50 \%$ probability level of ellipsoids. by direct methods using SIR $97^{19}$ and refined by full-matrix leastsquares on $\mathrm{F}^{2}$ with anisotropic displacement parameters for the non-H atoms using SHELXL-97. ${ }^{20}$ Structure analysis was aided by use of the programs PLATON98 ${ }^{21}$ and WinGX. ${ }^{22}$ Details of crystal data, data collection and structure refinement are listed in Table 2. Refinement of the site occupancy factors for the sulfide and selenide atoms confirmed the stoichiometry of the crystal.

\section{Results and discussion}

\section{Solid state structures}

Compounds 1-3 showed several intermolecular interactions in crystalline state (Fig. 2). In these compounds, dibenzophosphole

Table 1 Selected bond lengths and angles

\begin{tabular}{lllll}
\hline & $\mathbf{1}^{a}$ & $\mathbf{2}^{a}$ & $\mathbf{3}$ & Mixed Crystal \\
\hline $\mathrm{P}=\mathrm{X}$ & $1.4845(18)$ & $1.9545(11)$ & $2.1068(6)$ & $\begin{array}{l}1.986(9)[\mathrm{S}] \\
\end{array}$ \\
& & & & $2.079(3)[\mathrm{Se}]$ \\
$\mathrm{P}-\mathrm{C} 1$ & $1.803(3)$ & $1.804(3)$ & $1.8010(18)$ & $1.8025(13)$ \\
$\mathrm{P}-\mathrm{C} 12$ & $1.798(3)$ & $1.804(3)$ & $1.8125(18)$ & $1.8075(13)$ \\
$\mathrm{C} 1-\mathrm{C} 6$ & $1.393(3)$ & $1.395(4)$ & $1.408(3)$ & $1.4071(18)$ \\
C6-C7 & $1.479(4)$ & $1.475(4)$ & $1.481(3)$ & $1.4795(18)$ \\
C7-C12 & $1.404(4)$ & $1.406(4)$ & $1.398(3)$ & $1.4027(18)$ \\
C1-P-C12 & $92.24(12)$ & $92.03(14)$ & $91.94(8)$ & $92.04(6)$ \\
C1-P-C13 & $107.65(11)$ & $107.83(14)$ & $107.37(8)$ & $107.51(6)$ \\
C12-P-C13 & $108.02(12)$ & $107.51(13)$ & $107.92(8)$ & $107.75(6)$ \\
C1-P-X & $118.32(11)$ & $116.71(10)$ & $117.79(6)$ & $118.2(3)[\mathrm{S}]$ \\
& & & & $117.41(11)[\mathrm{Se}]$ \\
C12-P-X & $117.47(12)$ & $118.01(10)$ & $116.55(6)$ & $114.2(2)[\mathrm{S}]$ \\
& & & & $117.76(10)[\mathrm{Se}]$ \\
C13-P-X & $111.33(11)$ & $112.65(10)$ & $113.08(6)$ & $114.7(3)[\mathrm{S}]$ \\
& & & & $112.32(10)[\mathrm{Se}]$
\end{tabular}

${ }^{a}$ Ref. 15. 
cores adopt planar geometry and distorted tetrahedral $\mathrm{P}$ atoms with $\mathrm{C} 1-\mathrm{P} 1-\mathrm{C} 12$ angles of 91.9-92.2 ${ }^{\circ}$. The phosphorus-chalcogen bonds were found to display different length due to the covalent radius of chalcogen atoms. The $\mathrm{P}=\mathrm{O}$ bond length in $\mathbf{1}$ was found to be $1.4845(18) \AA$ while much longer bond lengths were found for $\mathrm{P}=\mathrm{S}$ in $2\{1.9545(11) \AA$ $\}$ and $\mathrm{P}=\mathrm{Se}$ in 3 $\{2.1068(6) \AA$ A .

The dihedral angles between the dibenzophosphole core and 9phenyl ring were slightly smaller than $90^{\circ}$ as $86.81^{\circ}$ in $1,83.08^{\circ}$ in 2 and $82.10^{\circ}$ in 3 . The $\pi-\pi$ interaction between two co-facial dibenzophosphole moieties was found to be $3.484 \AA$ in 2 \{Fig. 2 (b) $\}$. In compound $\mathbf{1}$, the observed offset of $\pi-\pi$ interactions was $3.344 \AA$ \{Fig. $2(a)\}$. The chalcogen-hydrogen interactions were

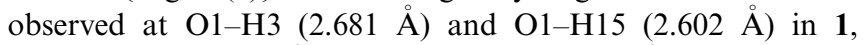
while $\mathrm{S} 1-\mathrm{H} 17$ (2.947 $\AA$ ) in $\mathbf{2}$ and Se1-H2 (3.089 $\AA$ ) and Se1-H17 (3.049 $\AA$ ) in 3.

\section{Mixed crystal}

The mixed crystal was prepared by slow evaporation from $\mathrm{CH}_{2} \mathrm{Cl}_{2} /$ hexane solution of the $1: 1$ mixture of $\mathbf{2}$ and 3. Fig. 3 shows an ORTEP structure of mixed crystal of $\mathbf{2}$ and $\mathbf{3}$ scaled to the 50\% probability level. The selected bond lengths and angles are summarized in Table 1 and crystallographic data and structural refinements are summarized in Table 2. The mixed crystal showed cell parameters similar to crystal 2. Compounds $\mathbf{2}$ and $\mathbf{3}$ are presumed to be randomly distributed in the mixed crystal due to the identical sizes and volumes of compounds 2 and 3 . The refinement for the site occupancy factors of $\mathrm{S}$ and Se indicated that the crystal was indeed a $1: 1$ mixture of 2 and 3 . This result was in good agreement with the mixed ratio obtained from the peak integration of ${ }^{31} \mathrm{P}$ NMR spectrum recorded upon re-dissolving the crystals. The bond lengths of $\mathrm{P}=\mathrm{S}$ and $\mathrm{P}=$ Se were found to be 1.986(9) $\AA$ and 2.079(3) $\AA$, respectively, both of which are close to the bond lengths of the single crystal of 2 $\left\{1.9545(11) \AA\right.$ \} and $3\left\{2.1068(6) \AA\right.$ \}. The dihedral angle of $87.71^{\circ}$ was identical to crystal 2.

Although the cell volume of the mixed crystal $\left\{1466.3(4) \AA^{3}\right\}$ was slightly larger than that of $2\left\{1456.3(2) \AA^{3}\right\}$ due to the presence of the selenium atom, the distance between two cofacial dibenzophosphole moieties in the mixed crystal (3.474 $\mathrm{A}$ ) was actually shorter than in the crystal of 2 (3.484 $\AA$ ). This shorter distance was attributed to the several $\mathrm{Se}-\mathrm{H}$ interactions (Se1-H2 with $2.984 \AA$, Se1-H9 with $3.066 \AA$, Se1-H10 with $3.055 \AA$ and $\mathrm{Se} 1-\mathrm{H} 17$ with $2.971 \AA$ ) in the mixed crystal (Fig. 4). This suggests that the mixed crystal of $\mathbf{2}$ and $\mathbf{3}$ comprises a larger number of intermolecular interactions than each of the crystals 2 or 3.

\section{Emission spectra in crystalline state}

Fig. 5 shows fluorescence and phosphorescence spectra of compounds 1-3 and the mixed crystal of $\mathbf{2}$ and $\mathbf{3}$ acquired in $\mathrm{CH}_{2} \mathrm{Cl}_{2} / \mathrm{MeOH}$ glass or single crystal at $77 \mathrm{~K}$. The emission data for all compounds were summarized in Table 3. The fluorescence of compounds 1-3 recorded in $\mathrm{CH}_{2} \mathrm{Cl}_{2} / \mathrm{MeOH}$ glass shows maxima located at 363-364 nm. However, in the compounds 2 and $\mathbf{3}$ the fluorescence was strongly suppressed due to the higher

Table 2 Crystal data and collection parameters

\begin{tabular}{|c|c|c|c|c|}
\hline & $\mathbf{1}^{a}$ & $2^{a}$ & 3 & Mixed Crystal \\
\hline Empirical formula & $\mathrm{C}_{18} \mathrm{H}_{13} \mathrm{OP}$ & $\mathrm{C}_{18} \mathrm{H}_{13} \mathrm{PS}$ & $\mathrm{C}_{18} \mathrm{H}_{13} \mathrm{PSe}$ & $\mathrm{C}_{36} \mathrm{H}_{26} \mathrm{P}_{2} \mathrm{SSe}$ \\
\hline Formula weight & 276.25 & 292.31 & 339.21 & 631.53 \\
\hline Wavelength /A & 0.71075 & 0.71075 & 0.71075 & 0.71075 \\
\hline Crystal system & Monoclinic & Monoclinic & Monoclinic & Monoclinic \\
\hline Space group & $\mathrm{P} 21 / \mathrm{c}$ & $\mathrm{P} 21 / \mathrm{c}$ & $\mathrm{P} 21 / \mathrm{c}$ & $\mathrm{P} 21 / \mathrm{c}$ \\
\hline$a / \AA$ & $10.0376(8)$ & $10.3764(10)$ & $10.377(2)$ & $10.320(2)$ \\
\hline$\alpha /^{\circ}$ & 90 & 90 & 90 & 90 \\
\hline$\beta /^{\circ}$ & $93.273(4)$ & $91.672(3)$ & $92.624(5)$ & $92.101(4)$ \\
\hline$\gamma /{ }^{\circ}$ & 90 & 90 & 90 & 90 \\
\hline$V / \AA^{3}$ & $1364.5(2)$ & $1456.3(2)$ & $1511.2(5)$ & $1466.3(4)$ \\
\hline $\mathrm{Z}$ & 4 & 4 & 4 & 2 \\
\hline$D$ (calc.) $/ \mathrm{g} \mathrm{cm}^{-3}$ & 1.345 & 1.333 & 1.491 & 1.430 \\
\hline$\mu / \mathrm{mm}^{-1}$ & 0.193 & 0.318 & 2.577 & 1.486 \\
\hline Independent reflections & 2399 & 2881 & 3460 & 3344 \\
\hline Completeness $/ \%$ & 99.8 & 97.8 & 99.7 & 99.6 \\
\hline Data/restraints/parameters & $2399 / 0 / 234$ & $2881 / 0 / 234$ & $3460 / 0 / 182$ & $3344 / 0 / 236$ \\
\hline Goodness of fit & 1.059 & 1.104 & 1.056 & 1.059 \\
\hline$R_{1}\{\mathrm{I}>2 \sigma(\mathrm{I})\}$ & 0.0476 & 0.0514 & 0.0277 & 0.0232 \\
\hline $\mathrm{w} R_{2}\{\mathrm{I}>2 \sigma(\mathrm{I})\}$ & 0.0979 & 0.0937 & 0.0658 & 0.0587 \\
\hline$R_{1}$ (all data) & 0.0797 & 0.0918 & 0.0321 & 0.0240 \\
\hline $\mathrm{w} R_{2}$ (all data) & 0.1147 & 0.1165 & 0.0679 & 0.0592 \\
\hline$\Delta r_{\max }, \Delta r_{\min } / \mathrm{e} \AA^{-3}$ & $0.260,-0.314$ & $0.478,-0.321$ & $0.35,-0.44$ & $0.348,-0.252$ \\
\hline
\end{tabular}

This journal is (C) The Royal Society of Chemistry 2011 


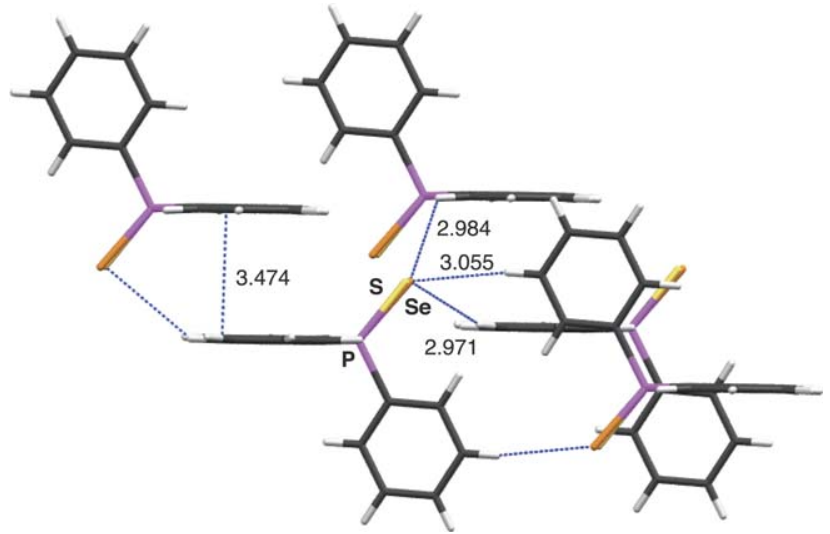

Fig. 4 Intermolecular interactions in mixed crystal of $\mathbf{2}$ and $\mathbf{3}$.

spin-orbit coupling of sulfur (2) and selenium (3). Compounds 1-3 exhibited nearly identical emission spectra with broad phosphorescence at 450-660 $\mathrm{nm}$. Due to the spin-orbit coupling of the chalcogen atom, the phosphorescence lifetime $\left(\tau_{\mathrm{Ph}}\right)$ for $\mathbf{3}$ of $0.54 \mathrm{~ms}$ was shorter than that of $\mathbf{1}\left(\tau_{\mathrm{Ph}}=312 \mathrm{~ms}\right)$ and 2 $\left(\tau_{\mathrm{Ph}}=21 \mathrm{~ms}\right)$.

The emission spectra of single crystals were observed at $77 \mathrm{~K}$. In the case of a single crystal, the fluorescence emission maximum of 1 was red-shifted by $16 \mathrm{~nm}$ compared to the spectrum recorded from glass. This red-shift is presumably due to the intermolecular interactions in the solid state. The phosphorescence spectrum was red-shifted by $6 \mathrm{~nm}$. Interestingly, the $\nu_{0-0}$ transition at $460 \mathrm{~nm}$ has almost disappeared and the emission maximum was shifted from wavelengths corresponding to the $\nu_{0-1}$ to $\nu_{0-2}$ transitions. The phosphorescence lifetime of the single crystal of $\mathbf{1}\left(\tau_{\mathrm{Ph}}=199 \mathrm{~ms}\right)$ was shortened by the intermolecular interactions relative to glass $\left(\tau_{\mathrm{Ph}}=312 \mathrm{~ms}\right)$. In the single crystals $\mathbf{2}$ or $\mathbf{3}$, the fluorescence and phosphorescence spectra were also red-shifted by $c a .23 \mathrm{~nm}$ (fluorescence) and

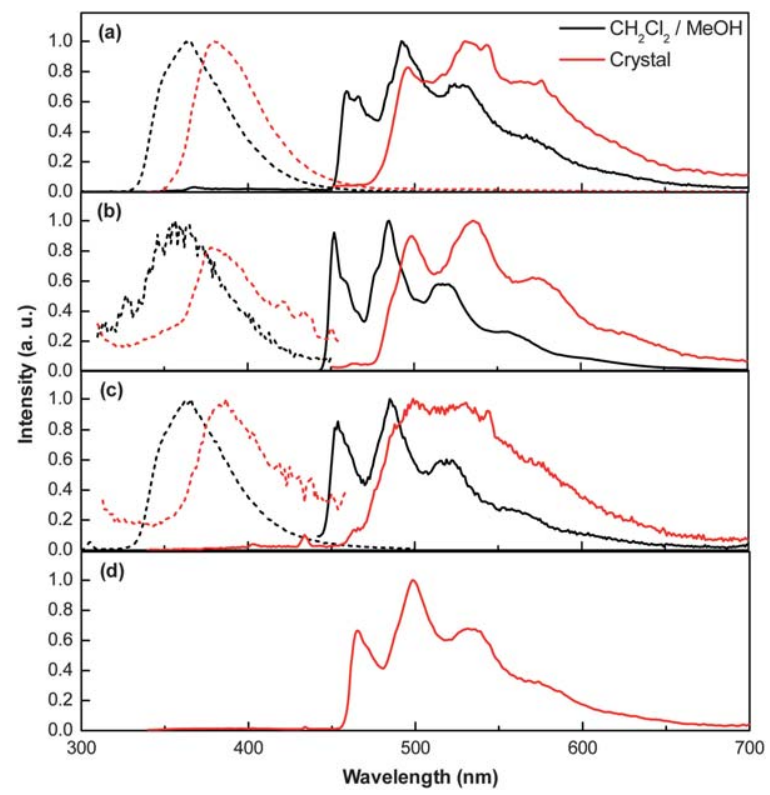

Fig. 5 Fluorescence (dashed line) and phosphorescence (solid line) spectra of 1 (a), 2 (b), 3 (c), and mixed crystal (d). The spectra were recorded in $\mathrm{CH}_{2} \mathrm{Cl}_{2} / \mathrm{MeOH}$ glass (black) and single crystal (red) at $77 \mathrm{~K}$.
Table 3 Phosphorescence emission maxima and lifetime at $77 \mathrm{~K}$

\begin{tabular}{|c|c|c|c|c|}
\hline & \multicolumn{2}{|c|}{$\lambda_{\mathrm{Ph}}(\mathrm{nm})$} & \multicolumn{2}{|l|}{$\tau_{\mathrm{Ph}}(\mathrm{ms})$} \\
\hline & Glass $^{a}$ & Crystal & Glass $^{a}$ & Crystal \\
\hline 1 & 492 & 530 & 312 & 199 \\
\hline 2 & 485 & 535 & 21 & 20 \\
\hline 3 & 485 & 534 & $\begin{array}{l}0.54(55 \%) \\
21.5(45 \%)\end{array}$ & $\begin{array}{l}0.41(81 \%) \\
5.30(19 \%)\end{array}$ \\
\hline Mixed Crystal & - & 498 & - & $\begin{array}{l}0.41(43 \%) \\
14.7(57 \%)\end{array}$ \\
\hline
\end{tabular}

$13 \mathrm{~nm}$ (phosphorescence), respectively. However, emission intensities of single crystals $\mathbf{2}$ or $\mathbf{3}$ were weaker than those of glass due to of the solid-state interactions. The $\tau_{\mathrm{Ph}}$ of single crystals of $2(20 \mathrm{~ms})$ and $\mathbf{3}(0.41 \mathrm{~ms})$ were slightly lower than the compounds in the glass (2: $21 \mathrm{~ms}, 3: 0.54 \mathrm{~ms}$ ). On the other hand, the mixed crystal of $\mathbf{2}$ and 3 showed only phosphorescence at $77 \mathrm{~K}$. Estimated from $\tau_{\mathrm{Ph}}=0.41 \mathrm{~ms}$, this phosphorescence was attributed to compound $3\left(\tau_{\mathrm{Ph}}=0.54 \mathrm{~ms}\right)$. Unlike single crystal 2 or 3, $\nu_{0-0}$ transition was observed and phosphorescence emission maximum was not $\nu_{0-2}$ but $\nu_{0-1}$. This spectral shape was close to that of glass. These results suggest that compound $\mathbf{2}$ may be acting as a rigid matrix and compound $\mathbf{3}$ as an emitter. ${ }^{11}$ Thus, one can avoid concentration quenching and reduce emissionshifting by using the mixed crystal approach.

\section{Conclusions}

The photoluminescence properties of crystals 1-3 and mixed crystal of $\mathbf{2}$ and $\mathbf{3}$ were investigated by their solid-state and X-ray structures. The X-ray structure indicated that the mixed crystal of $\mathbf{2}$ and $\mathbf{3}$ shows a higher number of intermolecular interactions (e.g. $\pi-\pi$ and $\mathrm{Se}-\mathrm{H}$ ) than each of the $\mathbf{2}$ or $\mathbf{3}$ single crystals. Unlike the single crystals of $\mathbf{2}$ or $\mathbf{3}$, the mixed crystal at low temperature exhibited only phosphorescence but not concentration quenching and emission-shift. Since the mixed crystal displays both desired properties, i.e. carrier transport and emission properties, this approach may be used in the future for optoelectronic applications such as in light-emitting SC-OFETs.

\section{Acknowledgements}

Financial support from AFOSR (Grant No. FA9550-05- 1-0276 to P.A.), the State of Ohio (WCI-PVIC), NSF (DMR-1006761 to P.A., EXP-LA 0731153 to P.A., CHE 0750303 to P.A.) and BGSU (P.A.) is gratefully acknowledged. NSF CRIF Grant No. 0741973 was used to purchase the X-ray diffractometers.

\section{Notes and references}

1 (a) J. Shinar, Ed. Organic Light -Emitting Devices, A Survey; AIP Press/Springer: New York, 2003; (b) Z. H. Kafafi, Ed. Organic Electroluminescence; CRC Press: Boca Raton, 2005; (c) Z. Li and H. Meng, ed. Organic Light -Emitting Materials and Devices; CRC Press: Boca Raton, FL, 2007; (d) H. Yersin, Ed. Highly Efficient OLEDs with Phosphorescent Materials; Wiley-VCH: Weinheim, Germany, 2008.

2 (a) J. Peet, A. J. Heeger and G. C. Bazan, Acc. Chem. Res., 2009, 42, 1700; (b) S. Gunes, H. Neugebauer and N. S. Sariciftci, Chem. Rev., 2007, 107, 1324. 
3 (a) C. A. Di, Y. Q. Liu, G. Yu and D. B. Zhu, Acc. Chem. Res., 2009, 42, 1573; (b) J. Zaumseil and H. Sirringhaus, Chem. Rev., 2007, 107, 1296; (c) A. R. Murphy and J. M. J. Frechet, Chem. Rev., 2007, 107, 1066; (d) V. Coropceanu, J. Cornil, D. A. da Silva, Y. Olivier, R. Silbey and J. L. Bredas, Chem. Rev., 2007, 107, 926.

4 H. E. Katz, Z. N. Bao and S. L. Gilat, Acc. Chem. Res., 2001, 34, 359 5 Y. Shirota and H. Kageyama, Chem. Rev., 2007, 107, 953.

6 V. C. Sundar, J. Zaumseil, V. Podzorov, E. Menard, R. L. Willett, T. Someya, M. E. Gershenson and J. A. Rogers, Science, 2004, 303, 1644.

7 (a) T. Takenobu, S. Bisri, T. Takahashi, M. Yahiro, C. Adachi and Y. Iwasa, Phys. Rev. Lett., 2008, 100, 066601; (b) H. Nakanotani, M. Saito, H. Nakamura and C. Adachi, Appl. Phys. Lett., 2009, 95, 033308; (c) Y. Yomogida, T. Takenobu, H. Shimotani, K. Sawabe, S. Z. Bisri, T. Yamao, S. Hotta and Y. Iwasa, Appl. Phys. Lett., 2010, 97, 173301; (d) S. Z. Bisri, T. Takenobu, Y. Yomogida, H. Shimotani, T. Yamao, S. Hotta and Y. Iwasa, Adv. Funct. Mater., 2009, 19, 1728.

8 R. Kabe, H. Nakanotani, T. Sakanoue, M. Yahiro and C. Adachi, Adv. Mater., 2009, 21, 4034.

9 R. Katoh, K. Suzuki, A. Furube, M. Kotani and K. Tokumaru, J. Phys. Chem. C, 2009, 113, 2961.

10 Y. Kawamura, K. Goushi, J. Brooks, J. J. Brown, H. Sasabe and C. Adachi, Appl. Phys. Lett., 2005, 86, 071104.

11 O. Bolton, K. Lee, H.-J. Kim, K. Y. Lin and J. Kim, Nat. Chem., 2011, 3, 205.
12 (a) H. Nakanotani, M. Saito, H. Nakamura and C. Adachi Adv, $A d v$. Funct. Mater., 2010, 20, 1610; (b) H. Li, L. Duan, D. Zhang, G. Dong, L. Wang and Y. Qiu, J. Cryst. Growth, 2008, 310, 2537.

13 H. C. Su, O. Fadhel, C. J. Yang, T. Y. Cho, C. Fave, M. Hissler, C. C. Wu and R. Reau, J. Am. Chem. Soc., 2006, 128, 983.

14 (a) Y. Ren, Y. Dienes, S. Hettel, M. Parvez, B. Hoge and T. Baumgartner, Organometallics, 2009, 28, 734; (b) Y. Dienes, U. Englert and T. Baumgartner, Z. Anorg. Allg. Chem., 2009, 635, 238; (c) Y. Dienes, M. Eggenstein, T. Karpati, T. C. Sutherland, L. Nyulaszi and T. Baumgartner, Chem.-Eur. J., 2008, 14, 9878; (d) T. Baumgartner and R. Reau, Chem. Rev., 2006, 106, 4681; (e) K. Geramita, J. Mcbee and T. D. Tilley, J. Org. Chem., 2009, 74, 820. 15 R. Kabe, C. Pérez-Bolívar and P. Anzenbacher, submitted.

16 S. Affandi, R. L. Green, B. T. Hsieh, M. S. Holt, J. H. Nelson and E. C. Alyea, Synth. React. Inorg., Met.-Org., Nano-Met. Chem., 1987, 17, 307.

17 Z. Otwinowski and W. Minor, Methods Enzymol., 1997, 276, 307. 18 Rigaku Americas Corportion, The Woodlands, TX, 2008.

19 A. Altomare, M. C. Burla, M. Camalli, G. L. Cascarano, C. Giacovazzo, A. Guagliardi, A. G. G. Moliterni, G. Polidori and R. Spagna, J. Appl. Crystallogr., 1999, 32, 115.

20 G. M. Sheldrick, Acta Crystallogr., Sect. A: Found. Crystallogr., 2008, 64, 112.

21 A. L. Spek, Acta Crystallogr., Sect. D: Biol. Crystallogr., 2009, 65, 148.

22 L. J. Farrugia and J. Appl, J. Appl. Crystallogr., 1999, 32, 837. 